\title{
A mediação dos saberes e o pensamento poético
}

\section{RESUMO}

O texto propõe uma problematização do pensamento comunicacional à luz de um pensamento poético. A comunicação é vista aqui a partir de um princípio de mediação nomeado de princípio com. Criadora de realidades, a poesia é também razão e pensamento, propiciadora do princípio com, uma força complexa que desperta, anima e movimenta. O texto inicia mostrando a ruptura histórica entre um modo de conhecimento científico-racional e um conhecimento poético que rapidamente é colocado à margem das reflexões científicas. Desenvolve o pensamento comunicacional que fundamenta a reflexão e apresenta a poesia como pensamento que deve enriquecer o pensamento da comunicação. Isso traz à tona alguns questionamentos epistemológicos que não são resolvidos aqui, mas inicialmente destacados como proposição.

\section{PALAVRAS-CHAVE}

- pensamento comunicacional

- poesia

- mediação dos saberes

\section{ABSTRACT}

The article proposes a problematization of communicational thought viewed from the angle of a poetical thought. Communication is seen here from a principle of mediation called com principle. Creator of realities, poetry is also reason and thought, supplier of the com principle, a complex force that awakens, animates and moves. The text starts showing the historical break between a scientificrational mode of knowledge and a poetic knowledge that is rapidly put aside of scientific reflections. The text develops the communicational thought that underlies reflection and presents poetry as a thought that must enrich the thought of communication. This brings to surface some epistemological questionings that are not solved here, but initially highlighted as proposals.

\section{KEY WORDS}

- communicational thougth

- poetry

- mediation of knowledge

\section{Florence Dravet}

UNB

\section{Gustavo de Castro e Silva UCB}

0 presente texto tem como objetivo apresentar uma proposta: pensar a comunicação mediante a poesia, com vistas a problematizar as condições de possibilidade de uma teoria da comunicação poética. Esta pesquisa teve início na Universidade Católica de Brasília (UCB), em 2004, a partir das leituras do estudo da relação poesia e linguagem em Martin Heidegger, desenvolvidas por professores e alunos do curso de Comunicação Social; foi ampliada através do grupo de estudos Poesia e Pensamento, em 2005, no Instituto Hermeum de Filosofia e Antropologia e, por fim, enseja a criação de um grupo de estudos, na UNB, de Poesia e Teoria da Comunicação.

Antes de mais nada, cremos ser necessário desbaratar a velha questão platônica apresentada no Livro X, de A República, sobre a necessidade da poesia. Essa questão aparecerá sempre como um problema a ser retomado quando o assunto é a da utilidade conceitual e científica da poesia. Poderão as Teorias da Comunicação servir-se dela? Terá alguma utilidade prática para o pensamento comunicacional? Tem ela algo a dizer às Teorias da Comunicação? E como explorar metodologicamente a Poesia na Comunicação? Não fossem todas essas questões, ainda temos outros dois grandes problemas a encaminhar:

1. Com qual conceito de poesia estamos trabalhando e;

2. Com que conceito de comunicação estamos operando?

Em nosso estudo, detectamos que poucas são as referências, dentro do pensamento comunicacional ou dentro das Teorias da Comunicação, que exploram notadamente a poesia. ${ }^{1}$ Não podemos dizer que as Teorias da Comunicação não se interessam pelas questões poéticas ou estéticas. Mas queremos ir além. É a poesia não só enquanto meio de expressão mas também enquanto pensamento que nos interessa diretamente aqui. Ao percorrer as diversas teorias conexas ao campo da comunicação em busca do espaço dedicado à poesia, encontramos na Teoria da Complexidade, de Edgar Morin, um lugar para essa dimensão da linguagem e da condição humana, ao lado da prosa. Morin chama a atenção para a importância de se reintegrar o encantamento e a poesia nas sociedades contemporâneas ocidentais onde rupturas sucessivas no pensamento provocaram, segundo ele, uma disjunção entre o estado poético e o prosaico e uma desvalorização do primeiro em prol do segundo. 
Houve duas rupturas. A primeira ocorreu a partir da Renascença, quando se desenvolveu uma poesia cada vez mais profana, ocorreu, igualmente, a partir do século XVII, uma outra dissociação entre uma cultura dita científica e técnica e uma cultura humanista, literária, incluindo a poesia. Foi a partir destas duas dissociações que a poesia autonomizou-se e tornou-se estritamente poesia. Separou-se da ciência, da técnica e, evidentemente, separou-se da prosa. (MORIN, Edgar. Amor poesia sabedoria. Trad. Edgard de Assis Carvalho. Rio de Janeiro: Bertrand Brasil, 4a. Ed. 2002, p. 37.)

Poesia, porém, não é apenas a dimensão simbólica, mítica, mágica e imaginária, o universo do devaneio, do sonho e da loucura distinto do universo lógico-tecnico-racional. Poesia é também pensamento, um pensamento-imagem que, segundo Roberto Juarroz, foi cindido em um dado momento da história em dois universos distintos.

Há um momento bastante crucial na história do espírito humano em que se separam o que poderíamos denominar o conteúdo do pensamento e o conteúdo do que hoje chamamos imagem. Extirpar o pensamento da criação poética a empobrece sem remédio, pois no homem o pensamento é insubstituível. A poesia além disso, não é simples razão ou simples sentimento, e é necessário recuperar a perda de unidade entre pensamento e imagem. Na poesia há imagem, mas também o que poderíamos designar, paradoxalmente, como imagem do pensar ou imagem de pensamento. (...) Para mim, o pensar é juntar o que alguma vez se dividiu, o que não somos capazes de fazer a toda hora do dia. Juntar o que alguma vez se fracionou absurdamente para explicar ou para raciocinar: aqui a ciência, a filosofia e ali o que é arte, poesia. (JUARROZ, Roberto. Poesía y creación. Buenos Aires: Carlos Lohlé, 1980, p. 39. Trad. dos autores)

Em grego antigo, poiesis é "fazer", "elaborar", "construir", aquilo que possibilita a criação ou a forma de linguagem que possibilita o novo e, a partir desse novo, permite que sejam tecidas as infinitas relações entre os vários níveis da realidade e da existência poeticamente tornada manifesta. $\mathrm{Na}$ comunicação como atividade perene do homem, a manifestação poética do ser convive intrínseca e permanentemente com a manifestação lógico-tecnicoracional desse mesmo ser. Por que então não atribuir à poesia o seu lugar dentro do pensamento sobre a comunicação? O que impede que, após a longa história das diversas rupturas e do profundo distanciamento entre o modo do conhecimento lógico-racional-científico e o modo poético da apreen- são da realidade, iniciemos agora o caminho de volta que religará os saberes desconexos da prosa e da poesia? Acaso, todo ato de comunicação não implica ao mesmo tempo o duplo movimento do pensar e do sentir? Quando pensamos, também não sentimos? E quando falamos, não estamos também imprimindo sentimento à nossa fala? Pensar uma coisa não é também senti-la?

\section{"existir não significa o que é visível ou o real, mas a unidualidade ou a monopolirealidade que alimenta todo existir"}

Não há ruptura na vida entre a atividade de pensar e de sentir, as duas coisas acontecem de uma só vez. Por isso, para pensar a comunicação, propomos pensar ao mesmo tempo os mecanismos conhecidos e explicados pela ciência e pensar o que não se explica e que somente o pensamento da poesia pode tornar cognoscível. Mas, afinal, para que serve a poesia? A dialogia poesia-conhecimento é de interesse para as ciências humanas porque a poesia serve como campo de investigação e ampliação do próprio conhecimento científico. Obedecidos o rigor e a pertinência, a poesia pode ser um campo de investigação em diversos níveis:

a. Na política, como expressão de resistência. A este respeito, Alfredo Bosi escreveu um capítulo paradigmático na história da literatura brasileira no seu Ser e Tempo da Poesia, ao tratar da poesia como ação politizante, não só uma resistência aos regimes totalitários, mas também à barbárie, a desordem, ao desencanto e ao caos cotidiano.

b. Na memória, como resgate e apreensão histórica. A poesia luta contra o esquecimento, favorece a pesquisa das mentalidades e das representações históricas, subsidia o respeito às tradições.

c. No conhecimento, como saber que franqueia imagens e idéias. Quando a idéia é associada a uma imagem, ela permanece infinitamente ativa e inexaurível. A poesia é uma doadora de sentido que coincide com a abertura do homem ao mundo e do homem a si mesmo. Nesse sentido, participa do universo do conhecimento humano - o universo de Sophia - que busca com-preender (partilhar conjuntamente o entendimento) dos sentidos múltiplos da natureza e do fazer (poiesis) humano. 
d. Na antropossociologia. Ao 'brincar' com o sentido de realidade, ela consegue desfazer os significados e 'refazer' o homem, situando-o noutro patamar. A poesia questiona o homem e a sociedade ante seus afetos, escolhas, racionalizações e estilos de vida. Há muito que a poesia moderna não consegue integrar-se, feliz, nos discursos correntes da sociedade. Compelida à estranheza e ao silêncio, ela penetra cada vez mais os rincões das buscas humanas essenciais.

e. Na arte e na linguagem: o caráter da palavra poética não se associa apenas ao seu aspecto icônico ou metafórico, mas também à mediação imagética e às diversas mediações discursivas: o tempo, o modo, a pessoa, o aspecto, faces todas que a predicação verbal e imagética configura.

f. Na mística: "a contemplação e a admiração da natureza com os sentidos mas também com o coração e o pensamento" 2 é a base da racionalidade poética na mística. A mística não descarta nada porque tudo pode ser via de acesso ao conhecimento mágico e sublime. Todos os elementos juntos oferecem aberturas que servem para dar sentido à vida, quando estão expressas em palavras que, no entrecruzamento de sensações diversas, resultam em efeitos numinosos, jogando luz sobre a vida daquele que comunga poeticamente a vida.

\section{Pensamento comunicacional: o princípio com}

A partir dos nossos estudos anteriores ${ }^{3}$ podemos definir a comunicação como o princípio animador e movimentador do existir; o fundamento da abertura, do despertar e do acompanhar do existir; o princípio com. Essa nossa noção nasce propriamente a partir de um pensamento poético, encontrado na poesia do poeta argentino Roberto Juarroz (19231995). Obviamente, não cabe aqui explorar a amplitude de tal conceito, o que em si mereceria um outro trabalho, este já desenvolvido no artigo $O$ Principio $\mathrm{com}^{4}{ }^{4} \mathrm{O}$ que devemos destacar dessa idéia é o entendimento da comunicação como um sistema aberto, paradoxalmente, em fluxos e nós que, enquanto princípio animador e movimentador, deve ser entendido como o que possui e propicia a conexão ou que, simplesmente, possui uma conexão aberta. O que significa tal conceito e quais os limites que ele abarca? A Comunicação é entendida aqui como eixo ou axioma conector necessário ao existir seja ele qual for. É o axioma conector do logos do espírito e do conhecimento (visto que, em grego, axioma e logos são designados pela mesma palavra). Existir não significa por sua vez o que é visível ou o real, mas a unidualidade ou a monopolirealidade que alimenta todo existir. Tal princípio, ao atuar, desperta as suas conexões, o seu acompanhar-de-si-em-conjunto, e são elas que tornam aquilo que ele é. O acompa- nhar-de-si-em-conjunto é outro nome para a unidade complexa que participa em todos os sistemas abertos. Cada unidade da matéria é acompanhada de si mesmo e de outros. Nada vive - feliz ou infelizmente - totalmente só. Provavelmente por isso o poeta Porchia dizia ao final das suas conversas com Juarroz: "Acompanhem-se".

Mas estas explicações ainda não atingem o limite do nosso conceito inicial aqui descrito. Tomemos, a título de esclarecimento, estas palavras: “O pensamento mais profundo sobre algo é também amor a esse algo. Passados certos limites, pensamento e amor são quase a mesma coisa. A poesia o sabe e o mostra". (Juarroz, Roberto. Decimocuarta poesia vertical. Buenos Aires: Emecé, 1997. §164/ Quase razão). Nas palavras de Juarroz sobre o "pensar profundo", ele chama a atenção para o "pensamento vertical". Pensamento e amor são quase a mesma coisa, diz ele, porque são os elos comunicativos mais fortes e flexíveis que o homem possui. Em todos os casos, elos conectores com as coisas e o mundo, mas também, e com a mesma intensidade, forças que, revestidas do seu contrário, apartam e dissociam. O pensamento mais profundo sobre algo então implica uma conexão com esse algo adentro e afora. O pensar que não é profundo não ama, logo não associa, não rejunta, nem reúne, mas disjunta e desune. E quem é o responsável por essa conexão profunda com esse algo? O pensamento? O amor? Que limites são necessários passar para que pensamento e amor sejam quase a mesma coisa? A resposta a todas estas questões está no fim do próprio fragmento: O poeta diz: "A poesia o sabe e o mostra". Mas então o que a poesia sabe e o que ela mostra? A poesia mostra que as conexões da natureza que são, simultaneamente, fortes e flexíveis são as que conseguem ultrapassar 'certos' limites. O pensamento profundo sobre algo só o é na medida em que possui conexões autoprodutoras e auto-realizadoras em si mesmo. O pensar profundo é o pensar amorosamente, isto é, o pensar que adota o princípio da religação ou o princípio com.

\section{"nem a ciência, nem a filosofia são produtoras de verdade, somente o é a poesia"}

O princípio com é, portanto, uma lei (nomos) de filiação, um logos que reúne, associa e acompanha, uma força complexa que desperta, anima e movimenta. Mas é também uma lei que rege as conexões não só porque em seu processo dinâmico flexibiliza as conexões, mas porque permite e coordena a abertura para novas fusões. Quanto mais aberto for à dinâmica o princípio com tanto mais ele tende ao risco da destruição quanto à conexão auto-produtora e auto-realizadora. A abertura é determinada pela 
capacidade de risco que se é capaz de correr ou de suportar, ou ainda a capacidade dele de se reorganizar. Sem o risco, contudo, a comunicação tende a se reproduzir, perde em criação e inicia um processo de encerramento-em-si. O princípio com é um princípio de manutenção da religação e a sua abertura, condição do existir. Tal princípio de manutenção é por sua vez um princípio de troca (conexões fortes e flexíveis) de matéria/energia. Uma caneca, uma pedra e um cachimbo estão em estado de equilíbrio com o meio, suas conexões são nulas, muito embora, imaginalmente, ocorram. Na imaginação humana, a caneca, a pedra e o cachimbo continuam a exercer ações diversas, trocas diversas, signos/símbolos diversos. Quando algo está em equilíbrio com o meio, sua tendência natural é ao desequilíbrio.

O aberto é o grande conceito esquecido pela ciência. Quase toda a filosofia também o esqueceu, com exceção de Martin Heidegger e Edgar Morin, muito embora os mais altos poetas-filósofos de nosso tempo tenham chamado a atenção para sua importância, entre eles, Hölderlin, Rilke e Juarroz. A princípio, duas idéias-chave decorrem do conceito de aberto: primeiro que as leis de organização e de manutenção do existir decorrem não do equilíbrio, mas do desequilíbrio. É o desequilíbrio o elemento propiciador do equilíbrio. A segunda idéia é a de que, para compreender o existir, devemos procurar as razões não apenas no próprio existir, mas também nas suas conexões, isto é, no princípio com. A realidade do existir está tanto no elo do existir consigo e com o aberto, quanto na distinção para com eles. O aberto implica o indeterminado, o risco, a conexão flexível; o fechado implica a autonomia, a segurança, a conexão rígida. O princípio com - em suas conexões flexíveis - possibilita trocas materiais/energéticas, organizacionais/informacionais e sapienciais/espirituais com o aberto. ${ }^{5}$

Se há uma lei que rege a comunicação, certamente ela poderá ser encontrada no princípio com. Esse princípio não se relaciona diretamente apenas com os fenômenos sócio-cotidianos mas principalmente com os campos de integração do existir, perpassando propriamente todo o existir. O pensar mais profundo e fundamental sobre a Comunicação é também um amor a esse pensar ou a essa Comunicação. Nietzsche disse certa vez que tudo o que é profundo ama a máscara. Não será assim também com a Comunicação? Ou ela não passa de um campo sem profundidades, sem fundamentos, sem essências?

\section{Pensamento poético: a razão-poesia}

Para expor a idéia de pensamento poético, precisamos de uma linguagem que se coloque à disposição da poesia, precisamos de conceitos e idéias abertos à poesia, por isso falaremos em conceitos-poéticos, idéias-poéticas. Como o conceito de Aberto criado por Rilke, ou o de Serenidade proposto por Heidegger, ou ainda como a idéia de Canto que pode definir a poesia. Para ser poético, pois, o pensamento precisa estar disponível e não pré-ocupado por uma linguagem anteriormente definida, usada e representada. O pensamento poético distingue-se do pensamento científico não só no fato de buscar conceitos-poéticos, mas também na ordem lógica de sua construção. Pensar poeticamente é deixar a poesia conduzir o pensamento, ou seja, efetuar uma inversão no movimento de construção lógica do raciocínio, permitindo que a indefinição, a ambigüidade ou o paradoxo permaneçam por mais tempo e abram os campos da cognição através do sensível. A idéia de Serenidade é, nesse sentido, um método, um caminho para o pensamento poético pois ela permite o aguardar da criação do sentido da palavra dentro da atividade de pensar. ${ }^{6}$

\section{"poesia originalmente é canto, e é enquanto canto que ela tem força poética"}

É importante salientar que, aqui, poesia não se reduz a nenhuma forma definida, podendo também estar presente na prosa e, ainda, na conversação. Assim também a concebe Octavio Paz, quando distingue o poema, a poesia e o poético:

Um soneto não é um poema, mas uma forma literária, exceto quando esse mecanismo retórico - estrofes, metros e rimas - foram tocados pela poesia. Há máquinas de rimar mas não de poetizar. Por outro lado, há poesia sem poema; paisagens, pessoas e fatos soam poéticos: são poesia sem ser poema. Pois bem, quando a poesia se dá como uma condensação do acaso ou é uma cristalização de poderes e circunstâncias alheios à vontade criadora do poeta, enfrentamos o poético. (PAZ, Octavio. El arco y la lira. $3^{\circ}$ ed. $14^{\circ}$ Reimpressão. México: Fondo de Cultura Economica, 2003. p. 14. Tradução dos autores.)

Se sua manifestação ideal se dá na língua, porque é nas palavras que ela encontra a conjunção necessária entre a significação e o canto (ritmo, harmonia, sonoridade, silêncio), ela também está presente em toda forma artística, onde constitui a sua essência fundamental. O que importa na poesia é que ela é o lugar da língua mais sagrado, o lugar do fundamento misterioso das coisas, aquele capaz de dar voz à linguagem, sendo que ela é a própria linguagem indo em direção à verdade. Muito mais do que forma e conteúdo, poesia é tida aqui como busca pela Revelação do Ser. Vista nesta perspectiva, ela é também a essência que fundamenta qualquer tipo de arte. 
Entendo que a poesia é algo assim como o humus, o substrato de toda forma de criação. Se a arte é criação, a arte tem um fundamento ou uma essência poética no fundo, qualquer que seja sua modalidade, seu gênero ou sua forma. (JUARROZ, Roberto. Poesía y creación. Buenos Aires: Carlos Lohlé, 1980, p. 29. Trad. dos autores)

Segundo Heidegger, somente a poesia é criadora de verdade na medida em que somente ela é capaz de criar na linguagem, ultrapassando os limites do conhecido, do representado, ou de efetuar uma "clareira" no Aberto. O Aberto: ${ }^{7}$ aquilo que não restringe, não impede, não tem limite; a grande totalidade de tudo o que não está restringido. A idéia de aberto é ambígua porque tanto significa "a totalidade dos nexos ilimitados da conexão pura", como significa a abertura "no sentido da ilimitação em que tudo vigora". O Aberto é também chamado por Rilke de círculo mais vasto, aquilo que circunscreve tudo que é, a circunscrição que circun-une todo ente. Ao efetuar uma clareira no aberto, o poeta traz a verdade que se encontrava oculta.

\section{"a poesia se apresenta como uma abertura epistemológica para o pensamento comunicacional que traz possibilidades metodológicas e teóricas ainda não exploradas"}

Isso significa que nem a ciência, nem a filosofia são produtoras de verdade, somente o é a poesia. Em "A origem da obra de arte", 8 Heidegger afirma que a ciência é o "desenvolvimento de um âmbito de verdade já aberto", que ela só desenvolve "aquilo que se prognostica como correto, quer possível, quer necessário" e que "se e na medida em que uma ciência vai para além do correto em direção a uma verdade" passa a ser filosofia. A poesia é então aquela capaz de efetuar a abertura necessária à inovação no pensamento. Por isso, é ela que permite mostrar aos homens uma verdade contida e revelada na palavra, através do exercício do pensamento. $\mathrm{O}$ pensador a oferece então à ciência para ser estudada em todos os seus desdobramentos. Poesia é pensamento e este deve confrontar-se poeticamente à poesia e a seus três poderes: poetizar, pensar, dizer.

A poesia tem algo a dizer e o diz com palavras que recebem a beleza do pensamento; esta beleza se afirma na poesia porque ela é a única maneira de recorrer às formas não desgastadas e vulgarizadas da língua. Nesta perspectiva, o poeta é o "dizente". Ele não é, de forma alguma, um mero instrumento passivo que cede passagem a palavras vindas de algum lugar enigmático. Ele é o ator principal na construção do elo entre a região enigmática onde se origina a linguagem e a própria fala no dito da poesia, na medida em que ele escuta e corresponde ao apelo primordial da linguagem.

Associa-se à beleza do pensamento do dizente uma outra dimensão fundamental para o sentido de conhecimento que a poesia propicia: a dimensão musical. Poesia originalmente é canto. E é enquanto canto que ela tem força poética. Um canto que só se explica - como a poesia - pelo próprio cantar; um canto que não se compreende, não se representa, mas tem um sentido contido em si que precisa ser apreendido na própria atividade de cantar. Tal canto possui um valor cognoscitivo, um sentido que acontece através da conjugação entre o som da palavra e o silêncio, através do agenciamento entre as sonoridades, através do jogo de ritmos e de sucessivas harmonias e desarmonias.

O canto também pertence a esse conjunto de saberes da poesia que nos fazem crer que ela não é puro delírio, devaneio, exercício de imaginação e libertação do esforço mental lógico-racional - um provável homo demens respondendo ao homo sapiens - , mas, ao contrário, que ela é uma forma de conhecimento e que existe na linguagem poética uma razão-poesia a ser movimentada, colocada em ação na apreensão da realidade. Uma razão-poesia presente em toda forma de linguagem, em todo ato de comunicação que precisa ter seu lugar no pensamento comunicacional porque ela tem o grande poder de não só apreender, mas de criar, construir realidades.

\section{Razão-poesia no e para o princípio com}

A poesia amplia o real porque constrói realidades. Ela não só abarca todo o real em sua forma de expressão, como também é criadora do real. Esta afirmação pode ser taxada de ingênua e idealista. Como se fosse uma resposta fácil à necessidade de sonhar com um lugar na atividade humana que concedesse ao homem o poder criador e esse lugar fosse naturalmente situado pelos sonhadores na poesia por ela ser linguagem criativa. Pensamos que interpretar de tal forma a afirmação é apreender o mundo de maneira fragmentar, dando ao homem apenas seu papel de cientista e filósofo, e não também o de artista e poeta. Nossa afirmação não é apenas a busca de realização de um sonho, trata-se da observação de uma realidade que quer devolver ao homem a sua unidade. Uma unidade do homem que é múltipla e pode sim ser dividida, mas somente na medida em que ela é, acima de tudo, unidade. Sendo assim, 
reiteramos: a poesia não é apenas linguagem criativa que atende à necessidade de expressão do ser humano, ela é criadora de realidades. O real é manifestação física, mas é também latência, é dado visível mas é também dado invisível, é universo conhecido mas é também mistério, é relação lógica entre as coisas, mas é também paradoxo inexplicável, o desconhecido, a infinitude.

Nesse sentido, na medida em que a palavra é o instrumento mais imediato e propício ao homem para traduzir o real e se comunicar, ela também é o elemento que lhe permite expressar o que é quase impossível expressar: o sentimento do mundo, o caráter angustiante de seus paradoxos e de sua infinitude. Tem-se então um desconhecido tornado conhecido, uma realidade desvelada na musicalidade da palavra-imagem.

Se poesia é contemplação do mundo, sensibilidade, imagem, som, ela contempla mundos por ela criados e, sendo assim, ela vai além da contemplação e se torna experiência, vida, sofrimento, gozo. Suas leis são suficientemente livres e abarcadoras para que ela possa propociar uma proximidade cada vez mais intensa com as leis misteriosas das conexões ilimitadas entre o homem e o aberto, designando ao mesmo tempo a experiência com os elementos do conjunto das coisas da conexão e aquilo que, de certa forma, todo homem já é.

É por isso que, enquanto criadora de realidades, a poesia é participante ativa do princípio com animador e movimentador do existir, na medida em que ela possui e propicia a conexão ou, simplesmente, possui uma conexão aberta com todas as coisas. Sendo síntese ou unidade de conhecimento que reúne em si palavra, imagem e som, ela funda, desperta e acompanha, criando presenças que acompanham o homem. Isso não é mais uma imagem poética que criamos como um encantamento para a nossa realidade. É uma imagem-pensamento sustentada pela idéia do "acompanhar-se" presente nos dizer de alguns poetas- filósofos como Antonio Porchia, René Char e Roberto Juarroz. Enquanto Char cria os Transparentes ${ }^{9}$ e deles se acompanha, Juarroz diz:

O que a poesia busca não é o confortável recurso de uma resposta, mas algo muito mais grave e mais importante para o homem, que é, diante da impossibilidade de respostas, criar presenças que o acompanhem. A poesia cria, não soluções, não fórmulas, nem receitas fáceis para a vida, mas companhia para a vida. (JUARROZ, Roberto. Poesía y creación. Buenos Aires: Carlos Lohlé, 1980, p. 28. Trad. dos autores)

\section{Caminhos do não-trilhado}

Não queremos apenas aqui pensar a poesia na comunicação como o fizeram com a arte e a literatura os expoentes do Cultural Studies e seus seguidores ou como vêm fazendo alguns grupos de pesquisa em Semiótica, queremos pensar poeticamente a comunicação como grande operador cognitivo e prático que determina os limites do conhecimento. A poesia se apresenta portanto para nós como uma abertura epistemológica para o pensamento comunicacional que traz possibilidades metodológicas e teóricas ainda não exploradas. Em termos metodológicos, o pensamento poético é um convite a seguir as vias da cognição sensorial e conceitual possibilitada pela palavra na poesia. Sendo assim, os caminhos do pensar poético tanto podem ser os da harmonia, da beleza e da serenidade como também, por serem caminhos do inexplorado, podem oferecer o risco de se perder ou de não chegar a lugar nenhum. Nesse sentido, são caminhos arriscados.

Isso se apresenta para nós como um desafio e um questionamento epistemológico que, por pouco, não nos paraliza ante o perigo que corremos. O perigo está justamente em propor tal possibilidade. Ao dizermos que entendemos a comunicação - enquanto techné - que opera a cognição e a ação do conhecer e do agir, e aliar a isso a unidade palavra-imagemsom sintetizadas na poesia, estamos levando a Teoria da Comunicação para horizontes pouco explorados, pelo menos no Brasil. Aqui, já não é o que a epistemologia da comunicação apreende das teorias e dos paradigmas presentes em outros campos do saber, mas o que os outros campos do saber têm a apreender de uma epistemologia da comunicação que avança sobre os seus próprio limites: o de perguntar à comunicação pela comunicação; o de que inquirir a comunicação sobre os seus fundamentos e essências, correndo o risco de nada encontrar. $\mathrm{O}$ princípio com é uma noção-risco que entende que nenhuma unidade é possível sem que haja nela e para ela um princípio que opere essa unidade, ou que pense as suas ligações, fusões, acordos, contatos ou contratos.

É por isso que fazer o pensamento comunicacional se aproximar da poesia é correr um duplo risco: o risco que se apresenta ao homem diante do perigo da amplitude do aberto, mas também o risco que se apresenta ao pensamento diante da ameaça da falta de rigor e do apelo ao delírio. É contra isso que lutamos. É por isso que, quando apresentamos nossa proposta em sucessivos fóruns de pensamento, somos alvejados não pelos "vigilantes cognitivos"10 mas pelos tautólogos e puristas. Os tautólogos defendem que a sucessiva repetição das teorias é o único modo de manter vivo o pensamento. Os puristas por acreditarem que elementos estranhos e indesejáveis ao campo devem ser eliminados. Nem um nem outro cabem na comunicação. Primeiro porque não é com a repetição que lançaremos olhares novos sobre velhos problemas, segundo porque poucas foram as ciências que dialogaram tanto no século XX com outros campos do saber quanto a comunicação. Para isso basta ver um congresso como este que ora se realiza. mfamecos 
NOTAS

1. A comunicação sempre foi pensada ou em seu aspecto histórico ou ligando-a a outros campos do saber. As linhas que mais se aproximam desta proposta foram o cultural studies por ter incluído a arte e a literatura na comunicação - ainda assim, esta foi submetida a uma visão marxista socio-antropológica e não foi pensada suficientemente como participação da arte no pensamento comunicacional - e, no Brasil, a folk-comunicação com os estudos da literatura de cordel.

2. Dravet, Florence. Em busca da verticalidade da palavra. Parte de livro em preparação sobre Poesia na Linguagem (Prelo).

3. Ver Castro, Gustavo e Dravet, Florence. Sob o céu da cultura. Brasília: Thesaurus/casa das Musas, 2004. Ver também Castro e Silva, Gustavo de. Filosofia da Comunicação. $2^{\circ}$ ed. Brasília: Casa das Musas, 2006.

4. Texto apresentado por Gustavo de Castro no livro em preparação da Universidade Católica de Brasília sobre Epistemologia da Comunicação

5. Ver CASTRO, Gustavo de et ali. Ensaios de complexidade. $4^{\circ}$ ed. Porto Alegre: Sulinas, 2006.

6. Idéia desenvolvida por Dravet, Florence no texto Pensar poeticamente - proposta metodológica para o pensamento comunicacional a partir de Martin Heidegger, apresentado para o livro em preparação na Universidade Católica de Brasília sobre Epistemologia da Comunicação.

7. Aberto: a noção aparece na poesia de Hölderlin e é retomada e ampliada por Rilke, tanto na sua poesia como em seus escritos sobre poesia. Heidegger, em seguida, desenvolve a idéia de Aberto no texto "Para quê poetas". In: Caminhos de floresta. Lisboa: Fundação Calouste Gulbenkian, 1998 (ed. or. 1959).

8. In: Heidegger, Martin. Caminhos de floresta. Lisboa: Fundação Calouste Gulbenkian, 1998 (ed. or. 1959), p. 64.

9. Ver A transparência, texto de Florence Dravet, desenvolvido no âmbito do estágio de pós-doutoramento em curso no Departamento de Teorias Literárias da UnB.

10. Termo criado por Edgar Morin para descrever os estudiosos que se colocam como guardas de fronteiras e vigiam as áreas do conhecimento a fim de impedir que elas sejam invadidas por aventureiros.

\section{REFERÊNCIAS}

BOSI, Alfredo. Ser e tempo da poesia. São Paulo: Companhia das Letras, 2000.

CASTRO E SILVA, Gustavo de. Filosofia da Comunicação. $2^{\circ}$ ed. Brasília: Casa das Musas, 2006.

CASTRO, Gustavo e DRAVET, Florence. Sob o céu da cultura. Brasília: Thesaurus/Casa das Musas, 2004.

HEIDEGGER, Martin. Caminhos de floresta. Lisboa: Fundação Calouste Gulbenkian, 1998 (ed. or. 1959).

JUARROZ, Roberto. Poesía y creación. Buenos Aires: Carlos Lohlé, 1980.

JUARROZ, Roberto. Decimocuarta poesía vertical, Buenos Aires: Emecé, 1997.

MORIN, Edgar. Amor poesia sabedoria. Trad. Edgard de Assis Carvalho. Rio de Janeiro: Bertrand Brasil, 4a. Ed. 2002.

PAZ, Octavio. El arco y la lira. $3^{\circ}$ ed. $14^{\circ}$ Reimpressão. México: Fondo de Cultura Economica, 2003. 